\title{
The 33rd International Geological Congress in Norway, 2008
}

\author{
(http://www.33igc.org)
}

\section{Introduction}

The 33rd International Geological Congress is organised jointly by the Nordic countries and held in Oslo, Norway, August 6-14, 2008. This "Geoscience World Congress 2008 " will run up to 40 parallel science sessions, poster sessions, an extensive exhibition, short-courses, workshops, and business meetings, as well as more than 50 exciting pre- and post Congress excursions. The excursions include all the Nordic countries, as well as Greenland, Svalbard, the Faeroes, Russia and Ukraine. All major geoscientific themes are being covered by the Congress. Through a series of "Themes of the Day", seven themes with major societal impact will be covered in plenary sessions with invited lecturers, including a key-note "StatoilHydro lecture" given each day during lunch-time. The venue is set up to offer a compact Congress with easy access to all sessions and other events. An extensive social and cultural programme is being prepared, and a series of short-courses, workshops, and business meetings will be arranged throughout the Congress.

Two major international events are closely related to the Congress. The International Polar Year (http://www.ipy.org) runs from 2007 to 2009, and with the Congress' strong emphasis on the Arctic, a close connection to IPY is natural. The International Year of Planet Earth (http://yearofplanetearth.org) was ratified by the UN General Assembly in 2005, and is also covering the period 2007-2009. The IYPE has chosen 10 main themes of focus, all with great societal importance. Several of these themes are also main themes of the Congress, and are treated in the full day plenary sessions in the "Themes of the Day".

The organisers of the 33rd IGC are honoured to have his Majesty the King of Norway as patron of the Congress. In addition, UNESCO has also offered its patronage. The Norwegian King's and UNESCO's support to the Congress clearly demonstrates how important the themes of the Congress are to society at large.

\section{Important deadlines}

15 Dec 2007: Geohost application deadline. 01 Feb 2008: Abstract submission deadline. 31 Mar 2008: Registration fee deadline for inclusion of accepted abstracts in the programme.

15 Apr 2008: End of early registration lowest fee.

15 July 2008: End of pre-Congress registration (only on-site registration possible thereafter).

06 Aug 2008: 33rd IGC opens.

\section{The Science Programme}

Symposium

The scientific programme of the Congress was initiated mainly through a "bottomup process", in which the global geoscience community was invited to propose symposia. This resulted in more than 600 suggestions. After further work by the Science Committee, a total of roughly 450 symposia were presented in the science programme when registration opened on September 1, 2007. Good suggestions for symposia are still welcomed, however, as the aim is to have as comprehensive and good a science programme as possible during the 33rd IGC.

Three categories of Symposia are being arranged, referred to as General (Disciplinary), Special (Regional) and Topical (Interdisciplinary). They will run in parallel throughout the Conference. The time allocated to each symposium will be dependent on the number of related contributions (abstracts) received by 1st February 2008. Division of these symposia contributions between oral and poster presentations will depend on the recommendations of the conveners and the capacity of the ca. 40 parallel sessions.

General Symposia will cover all the main Geoscience disciplines. They are organised in related groups to allow easy navigation within the overall programme. A group of coordinators was selected to coordinate the submission of symposia within broad geoscientific topics. These coordinators also act as convenors for some of the symposia within their topic. Special Symposia are dedicated to Regional Geology and include all the continents-Africa, Asia, Europe, North America, South America and Oceania (including Australia and Antarctica). The Arctic symposia are included within these Special symposia, as is the particular Nordic flavour of the Congress. Likewise, global geological projects are organised in this category. Topical Symposia are of interdisciplinary character and cover a very wide range of subjects that are of particular interest for Earth Science today. They range from basic geoscience, to societal issues and managerial-organizational problems. All aspects of the International Year of Planet Earth (IYPE) will have a place amongst these symposia. Themes such as natural hazards, climate change, biogeosciences, petroleum geosciences, mineral deposits, hydrogeology, exploration geophysics, palaeontology, energy, environmental geosciences, and many others have a wide variety of symposia. The programme is frequently updated on the website (www.33igc.org).
Themes of the day

Seven themes of main importance in the geosciences have been chosen to be given particular priority. These themes each have a dedicated day of the Congress (see below), and a plenary lecture hall is allocated for these "Themes of the day" sessions. Each day is divided in a morning session with presentations on the purely scientific aspects of the theme. During the 2 hour lunch-break a keynote lecture (the "StatoilHydro Lecture") on the subject is given by a highly profiled lecturer. This is followed by the afternoon session, in which societal, political and economic aspects of the theme are treated. The day ends with a panel debate and a press conference. All presentations are given by invited lecturers, and ministers from the Nordic governments are invited to open the sessions. Programme for the "Themes of the day" at the 33rd IGC:

07 Aug (Thu): Early life and survival of the fittest - biodiversity and the geoenvironment

08 Aug (Fri): Climate change: past, present, future

09 Aug (Sat): Geohazards and human behaviour

11 Aug (Mon): Water, human health and the environment

12 Aug (Tue): Mineral resources in a fast-growing global economy are there any natural limits?

13 Aug (Wed): The energy race - what will be the future energy mix?

14 Aug (Thu): Earth and beyond synergies between Earth and planetary sciences

\section{Excursions}

More than 50 pre- and post Congress excursions are being prepared. These cover all the Nordic Countries, including Iceland and the Faeroe Islands. In addition, there are excursions to Svalbard, Greenland, NW Russia and Ukraine. The length of the excursions varies from 2-3 days up to nearly 2 weeks, and the price varies according to duration and area. One-day excursions in the Oslo area will be arranged during the Congress. The committee has strived to keep the prices of excursions as reasonable as possible, and some of the more expensive ones are being sponsored to reduce the price for the participants. The excursions cover the width of Nordic and Arctic geology, and will also give the participants insight in the natural and cultural heritage of the regions they cover. Most of the excursions go through magnificent scenery and are very well suited as vacation 
targets! Examples are many, such as excursion no. 31 covering parts of the fjord landscape on the west coast of Norway, which are included in the UNESCO World Heritage List, or no.5, covering a large part of scenic Iceland. Excursion no.44 is the grand trip around the Arctic archipelago of Svalbard, considered an extremely exotic travel target by many. Another exotic area are the Faeroes Islands, which are covered by excursion nos. 5 and 6 . This will be the ultimate field trip for those who want to combine the special scenery of the archipelago with close studies of basalts and sediments on a passive continental margin, sculptured by glaciations.

\section{Workshops, Short Courses and Business Meetings}

A wide range of short (single-day) courses have been proposed. These will be run by experienced lecturers and are designed for all who wish to widen their knowledge of particular subjects. Workshops provide an opportunity for specialists to discuss particular subjects that are less suitable for symposia. Workshops and short-courses are announced on the website, and participants must register for these. Many of the commissions, projects, and affiliated associations of IUGS hold business meetings at IGC. In addition, the Organising Committee encourage other associations, companies, etc. to hold their meetings during the Congress. Provided the meeting delegates are registered for the Congress, rooms are provided free of charge. The workshops, shortcourses, and business meetings will primarily be concentrated to Sunday 10 August, but may also be arranged at other times, following requirements and availability of rooms.

\section{"GEOEXPO" Exhibition}

An area of more than $2500 \mathrm{~m}^{2}$ of the venue is dedicated for the exhibition. The aim is that the GeoExpo exhibition at the 33rd International Geological Congress should be one of the largest and most valuable exhibitions for all geo-related industry as well as for all governmental and private organisations operating in the geosciences. The exhibition will be located in the same hall as the poster presentations, and will be a natural meeting point. Exhibitors will be clustered in "villages" where visitors can scan through geological surveys of the world, universities, science publishers, computer companies, consultancies, oil companies, etc.

\section{Social and Cultural Programme}

We aim at providing a good social and cultural programme for the thousands of participants from all over the world coming to the 33rd IGC. The events, all announced on the website, include opening and closing ceremonies, icebreaker party, a night in the new Oslo Opera House, rock/jazz club, and an outdoor barbeque party in the Oslo Botanical Gardens. The cultural programme during the ceremonies will show the participants elements of the cultural life in all the five Nordic countries. In addition to the official programme, Oslo is a lively city with numerous bars, restaurants, and music clubs. There is no reason not to have a good time in Oslo in August 2008, also outside of the Congress hours.

\section{The Geohost Stipend Programme for Developing Countries}

\section{Deadline: December 15, 2007}

The Geohost Programme is dedicated to help individual scientists and students primarily from developing countries to attend the Congress by partially subsidising their expenses. Each applicant to the Geohost Programme may request a subsidy for one or more of the following: registration fee for the Congress; the registration fee for a Workshop or a Short Course, subsidised accommodation during the Congress, and the fee for a field trip. Applicants will be selected using the following criteria: submitted abstract, scientific qualifications and financial need, as documented in a letter from the supervisor or chairperson. Priority will be given to younger scientists and graduate students with proven academic attainments. The deadline for Geohost applications is December 15,2007 , and the necessary information is found on the website.

http://www.33igc.org/

\section{Final work}

The IGCs are arranged only every four years. The 33rd IGC is much more than "just another huge geo-conference", with its large and exciting excursion programme, the many workshops, short-courses, business meetings, and the varied cultural and social programme. The last IGCs have seen a steady increase in the number of participants, and we aim at continuing this trend. Our major goal is to provide a good Congress where important topics have been discussed and the forefront of the whole width of geoscientific research has been demonstrated.

See the website for updated information: http://www.33igc.org

\section{Anders Solheim}

33rd IGC Secretary General

\section{Sylvi Haldorsen}

IUGS Vice President

November 30, 2007

\title{
CALL FOR PAPERS
}

Episodes is the quarterly science and news journal of the International Union of Geological Sciences (IUGS). It focuses on the publication of results of scientific research and other information addressing issues of interest to the global earth-science community. Special emphasis is given to topics involving geological aspects of population growth and economic development and their resulting impacts on or implications for society. As the principal publication of the IUGS, Episodes also carries information about IUGS scientific programs and activities to the extent necessary to communicate effectively with the worldwide IUGS constituency.

Contributions of the following types of manuscripts are here solicited:

- review papers

- scientific articles

- conference reports

- news and views

- letters to editor

- book reviews

- information on training courses (especially those geared to participants from developing countries)

- noteworthy new publications, including national or regional geologic maps

Please address all contributions to:

\author{
Episodes \\ P. O. Box 823, 26 Baiwanzhuang Road \\ 100037 Beijing, CHINA \\ Tel: +86-10-68320827, +86-10-68329084 \\ Fax: +86-10-68328928 \\ E-mail: episodes.journal@yahoo.com
}

